\title{
Prediction of Moisture Content Changes during Natural Drying of Forest Residues Using Load-cell-mounted Drying Platforms
}

\author{
Yun-Sung Choi, ${ }^{1}$ In-Seon Jeong, ${ }^{1}$ Min-Jae Cho, ${ }^{1}$ \\ Ho-Seong Mun, ${ }^{1}$ Jae-Heun Oh, ${ }^{1}$ and Sang-Kyun Han $^{2 *}$ \\ ${ }^{1}$ Forest Technology and Management Research Center, National Institute of Forest Science, \\ 498, Gwangneungsumogwon-ro, Soheul-eup, Pocheon-si, Gyeonggi-do 11186, South Korea \\ ${ }^{2}$ Division of Forest Sciences, College of Forest and Environmental Sciences, Kangwon National University, \\ 1, Kangwondaehak-gil, Chuncheon-si, Gangwon-do 24341, South Korea
}

(Received August 30, 2021; accepted October 25, 2021)

Keywords: forest biomass, woody fuel, comminution, prediction model, biomass energy

The use of renewable energy has increased markedly with growing global efforts to reduce fossil carbon emissions. Among various renewable energy sources, forest residues produced from timber harvesting are considered effective energy production sources. The combustion effectiveness of forest residues is highly affected by their quality, particularly their moisture content. However, determining when forest residues reach the target moisture content $(<30 \%)$ during natural drying is a challenge to forest managers. Therefore, in this study, we investigated the changes in moisture content during the natural drying of forest residues and developed a prediction model for estimating the changes in moisture content using meteorological factors. The changes in moisture content had similar patterns to the changes in precipitation during the natural drying of forest residues, and the minimum natural drying time required to reach the target moisture content was approximately 26 days in summer. A prediction model for estimating the changes in moisture content was developed using meteorological factors including precipitation, wind speed, effective humidity, and solar radiation quantity; the average absolute difference between the measured and predicted moisture contents was $22.7 \%$ in the model validation. Although the developed prediction model has limited accuracy in estimating the precise moisture content of forest residues during natural drying, it could aid forest managers to roughly determine the appropriate production and transportation times of forest residues for energy production.

\section{Introduction}

With increasing global concerns over climate change, the use of renewable energy sources such as hydropower, wind, solar, and woody biomass has been gradually increasing to reduce fossil carbon emissions. In South Korea, renewable energy accounted for approximately $6 \%$ of the total energy consumption in 2018 , and the government plans to increase the share of

*Corresponding author: e-mail: hsk@kangwon.ac.kr https://doi.org/10.18494/SAM.2021.3608 
renewable energy to $20 \%$ by 2030 . $^{(1)}$ To achieve this target, woody biomass has been considered a valuable energy source for replacing fossil fuels owing to its domestic abundance, sustainable supply chains, and carbon neutrality. $(2,3)$

Woody biomass for energy production is primarily classified into forest residues, mill residue, and urban wood waste. Forest residues are the single largest source of woody biomass energy and originate primarily from timber harvests, thinning treatments, tree treatments due to pest damage, and forest restoration. Forest residues generated during timber harvesting generally include small branches, tree tops, and some decayed wood from harvested trees. In addition, forest residues are characterized by the irregular shape and size of the materials and the mixed species of harvested trees. These characteristics imply that using forest residues generates additional handling efforts for extraction, transportation, comminution, and storage, and high production costs typically restrict the use of forest residues for energy production.

The moisture content of woody biomass is also one of the most important factors in biomass utilization, as it directly affects energy production as well as the transport and storage of biomass materials. $^{(4,5)}$ Forest residues produced after timber harvesting generally contain abundant moisture, approximately $50-60 \%$ of the total weight. The high moisture content adversely affects the combustion efficiency of woody biomass fuel by consuming energy through the absorption of evaporative heat. ${ }^{(4,6)}$ Therefore, a sufficient reduction in moisture content is required for the efficient use of woody biomass fuel. The Korea Forest Service has stipulated that high-quality wood chips must have a wet-based moisture content of $<20 \%$. ${ }^{(7)}$

In addition, the moisture content of woody biomass is considered important for its storage. ${ }^{(8)}$ In general, woody biomass cannot be used immediately after production and should be stored for a certain period. During the storage period, a high moisture content typically increases the internal temperature of the loaded fuel during storage, creating suitable conditions for mold and bacterial propagation. ${ }^{(9,10)}$ Brischke and Rapp ${ }^{(11)}$ reported that the optimum conditions for mold growth are a temperature of $20-30{ }^{\circ} \mathrm{C}$ and a moisture content of $30-50 \%$. Therefore, the storage of woody biomass under these environmental conditions could promote the anaerobic fermentation of mold and reduce the overall fuel quality for energy production, as well as reduce the dry weight and heat quantity.

The high production costs of woody biomass are also closely related to the moisture content of raw materials. ${ }^{(4)}$ In forest biomass production, transportation costs account for $31-46 \%$ of the total production cost, ${ }^{(12)}$ and reducing the weight-to-volume ratio of loaded materials could markedly reduce the overall cost of forest biomass production. ${ }^{(13)}$ Strandgard et al. ${ }^{(14)}$ revealed that the total production cost of wood chips can be reduced by up to $28-30 \%$ by reducing the water content. Therefore, a drying process for reducing moisture content is essential for the forest biomass supply chain.

There are two representative drying methods for woody residue: artificial drying and natural drying. Natural drying is widely used for forest biomass because it is cheaper and easier to attain a suitable moisture content for field production than by using artificial drying methods. ${ }^{(15)}$ However, there are also limitations in the natural drying method, which requires a long time (approximately 3 to 6 months under normal conditions) and is strongly affected by meteorological factors. Natural drying causes fluctuations in moisture content during the drying period. ${ }^{(4,6)}$ 
Hence, it is difficult for producers to know the exact time when the object reaches the target moisture content, which can decrease the efficiency of the entire forest biomass production process. ${ }^{(16)}$ The optimization of the drying time and period is crucial to achieving economical forest biomass production.

With the growing need for woody biomass fuel worldwide, efficient production and supply have become important. In particular, the control of the moisture content in raw materials is one of the key factors for forest biomass utilization. In this study, we investigated the changes in the moisture content of forest biomass during natural drying in the field using metal frame load cells and estimated the appropriate natural drying time considering the meteorological factors in the field. The specific objectives were to investigate the variations in moisture content during the natural drying of forest residues produced from clear-cutting and to develop a model for predicting the variations in moisture content with meteorological factors using the acquired data.

\section{Materials and Methods}

\subsection{Materials and measurements}

This study was conducted using the forest residues left on the mountains after the line thinning of the Korean pine (Pinus koraiensis) forest located at San 154-1 (38 0024.7"N $\left.127^{\circ} 4813.8^{\prime \prime E}\right)$, Gancheok-ri, Gandong-myeon, Hwacheon-gun, Gangwon-do. We selected one of the stacked piles of forest residues in the timber harvesting field and measured the changes in moisture content during natural drying from early summer (June 27, 2018) to early fall (October $2,2018)$. The pile of forest residues consisted of stems (34\%), branches (41\%), and leaves (38\%).

Special natural drying platforms for monitoring the changes in moisture content in forest residues were installed on the forest road, as shown in Fig. 1. These platforms comprised frames,

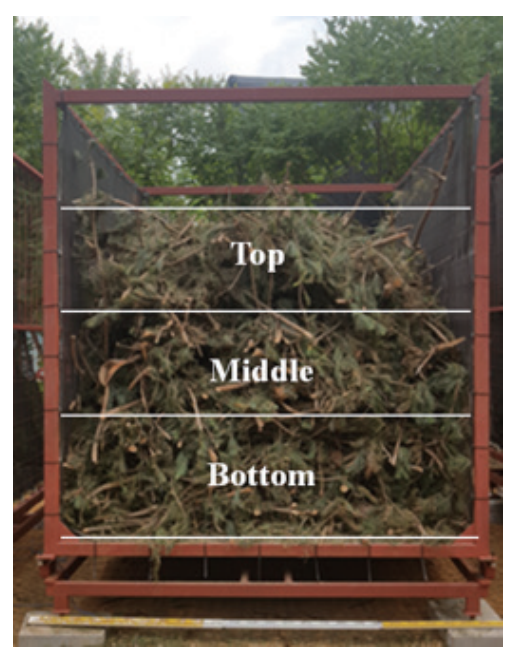

(a)

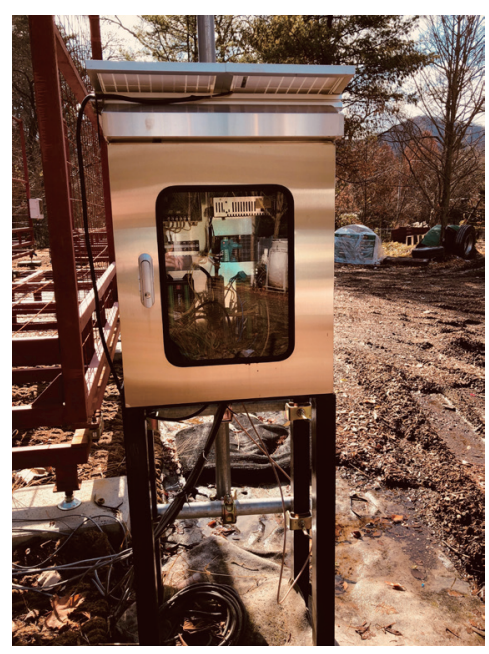

(b)

Fig. 1. (Color online) Metal frame with load cells (a) and data logging device (b) for weighing forest biomass during natural drying. 
measuring devices, and data logging devices. The dimensions of a frame were $2.5 \times 2.6 \times 2.8 \mathrm{~m}$. A measuring device consisted of a load cell, a summing box (Cas, JB-PA, Korea), and an indicator (Cas, CI-1580A, Korea). Load cells were installed at the lower corners of the equipment, and the weight of forest residues was continuously measured. The weight of forest residues measured at four load cells was integrated into the summing box to be transmitted to the indicator. The measured weight data were also programmed to be transmitted and recorded via a wireless transmitter (Parani, SD-100, Korea) at $1 \mathrm{~h}$ intervals.

In the natural drying of forest residues, the drying time and period are closely related to the meteorological conditions in the field. In the present study, 11 types of weather data, namely, evaporation-precipitation (E-P), precipitation, evaporation, solar radiation quantity, cloud, wind speed, effective humidity, atmospheric temperature, ground-surface temperature, spot atmospheric pressure, and humidity, were considered as parameters affecting the changes in the moisture content of forest residues. These parameters were also used to develop a prediction model for the moisture content of forest residues. The meteorological parameters were collected from the Open Climate Data Center. However, the experimental site was $27.6 \mathrm{~km}$ from the nearest meteorological station in Seoul and was limited in the preciseness of the received meteorological information. Therefore, we integrated data from Seoul Meteorological Observatory $\left(37^{\circ} 3417.9^{\prime \prime} \mathrm{N} 126^{\circ} 5758.4^{\prime \prime} \mathrm{E}\right)$ and Chuncheon Meteorological Observatory $\left(37^{\circ} 5650.9^{\prime \prime} \mathrm{N} 127^{\circ} 4525.3^{\prime \prime} \mathrm{E}\right)$ using linear interpolation [Eq. (1), Fig. 2]. In addition, $70 \%$ of the collected meteorological data were used for model building and the remaining $30 \%$ were used for model validation.

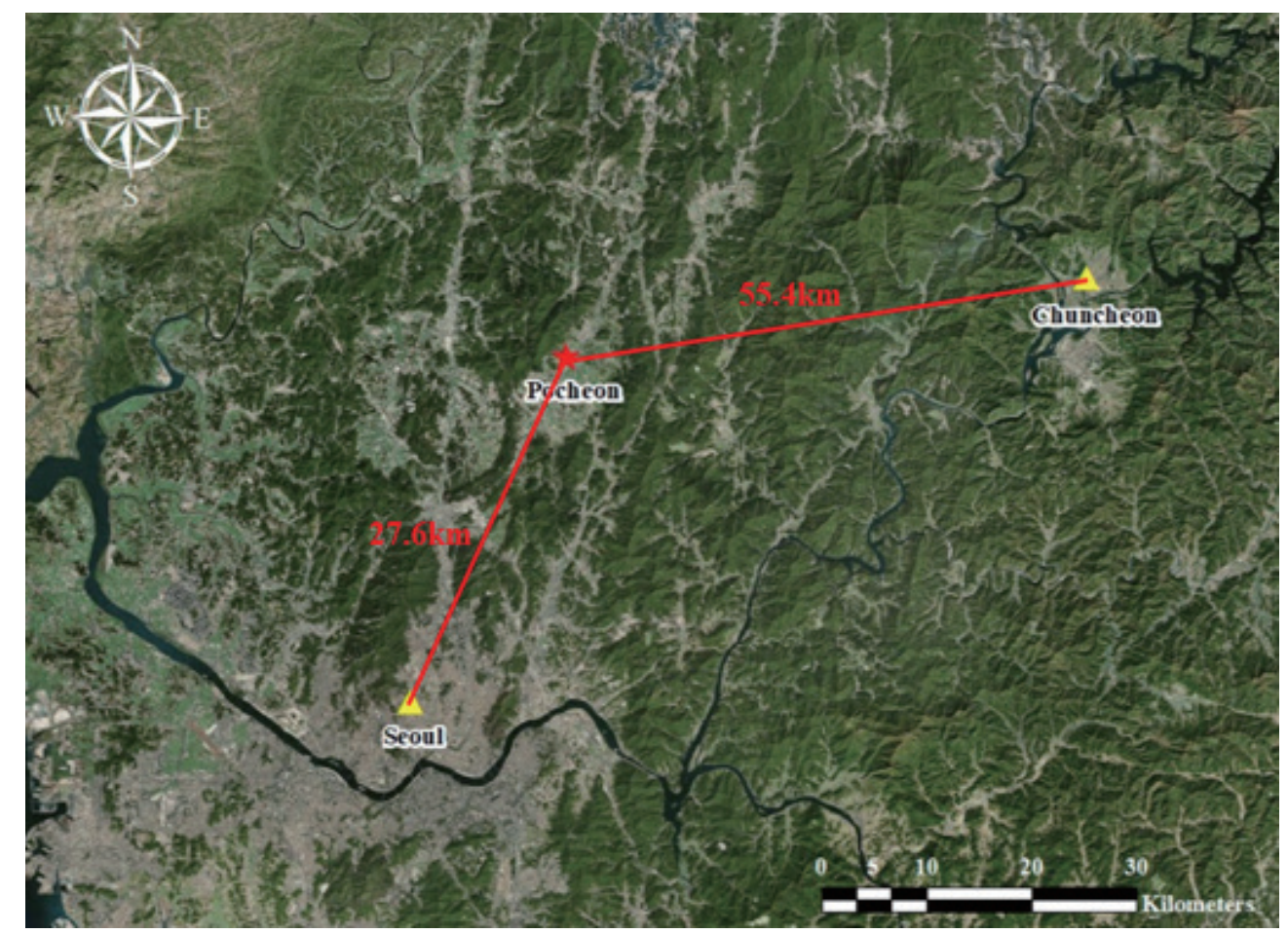

Fig. 2. (Color online) Meteorological data collection. 


$$
f(p)=\frac{d_{2}}{d_{1}+d_{2}} f\left(p_{1}\right)+\frac{d_{1}}{d_{1}+d_{2}} f\left(p_{2}\right)
$$

Here, $d_{1}$ is the distance from $p$ to $p_{1}$ and $d_{2}$ is the distance from $p$ to $p_{2}$.

\subsection{Prediction model development}

In general, the accuracy of the prediction model was strongly affected by independent input variables. In the development of the prediction model, the critical variables that correlated with moisture content were selected from 11 meteorological parameters by correlation analysis.

$$
M C_{i}=\left(M C_{i-1}\right)+\beta_{1} x_{1}+\beta_{2} x_{2}+\cdots+\beta_{k} x_{k}+c
$$

Here, $M C_{i}$ is the moisture content, $\beta_{n}$ is the coefficient, and $x_{n}$ is the meteorological parameter.

Despite the strong relationship with the moisture content, the error rate of the prediction model was typically high because of the multi-collinearity between significant variables. Therefore, we first tested the multi-collinearity of each variable and removed the variables (E-P, Evaporation) found to be correlated with the model. Finally, we implemented the backward elimination technique to obtain the optimal prediction model with the minimum error sum of squares [SSE, Eq. (2)].

$$
t^{*}=\frac{\bar{D}}{S_{\bar{D}}}
$$

Here, $t^{*}$ is the t-statistic, $\bar{D}$ is the mean of the difference in moisture content change between the predicted and measured data, and $S_{\bar{D}}$ is the standard error for the mean of the difference in moisture content.

$$
R M S E=\sqrt{\frac{\sum_{i=1}^{n}\left(x_{\text {measured }, i}-x_{\text {predicted }, i}\right)}{n}}
$$

Here, $N$ is the number of data.

To examine the validity of the developed prediction model, a $t$-test and root mean square error (RMSE) analysis were conducted between the measured moisture content and the moisture content estimated from the prediction model using the remaining $30 \%$ of the test data [Eqs. (3) and (4)]. After the error rate analysis, the test data were included in the model to enhance its accuracy. ${ }^{(17,18)}$ 


\subsection{Validation of prediction model}

To additionally validate the final prediction model, another harvesting site was selected with similar stand conditions (Korean pine stand) and a harvesting method (clear-cutting) similar to those of the first study site. A total of 45 piles of forest residues were built on the harvesting sites, and all the test piles were subsequently comminuted for six months to measure the changes in moisture content for each forest residue pile. After the comminution of each pile, three wood chip samples (approximately $500 \mathrm{~g}$ per sample) were collected and dried via oven drying (ISO 18134-1:2015, Switzerland) to acquire the moisture content data (Fig. 3).

In addition, the meteorological data were collected using the same method as for the previous study period of seven months (from September 27, 2019 to April 16, 2020). In the prediction model validation, the moisture content predicted from the final model was compared with that measured via oven drying. Consequently, the mean error rate was calculated for each pile, and cause analysis was conducted on the errors [Eq. (5)].

$$
E_{p}^{*}=\frac{\left|M C_{p}-M C_{o d}\right|}{M C_{o d}} \times 100
$$

Here, $E_{p}^{*}$ is the error of the moisture content predicted by the model, $M C_{p}$ is the moisture content predicted by the model, and $M C_{o d}$ is the moisture content measured via oven drying.

\section{Results and Discussion}

\subsection{Changes in moisture content for forest residues during natural drying}

The changes in moisture content were investigated for three months from early summer to early fall. In the present study, the target moisture content of forest residues was approximately

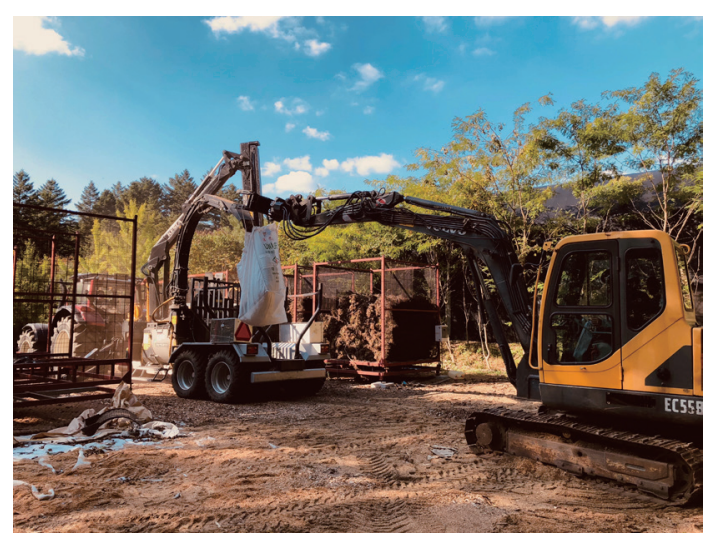

(a)

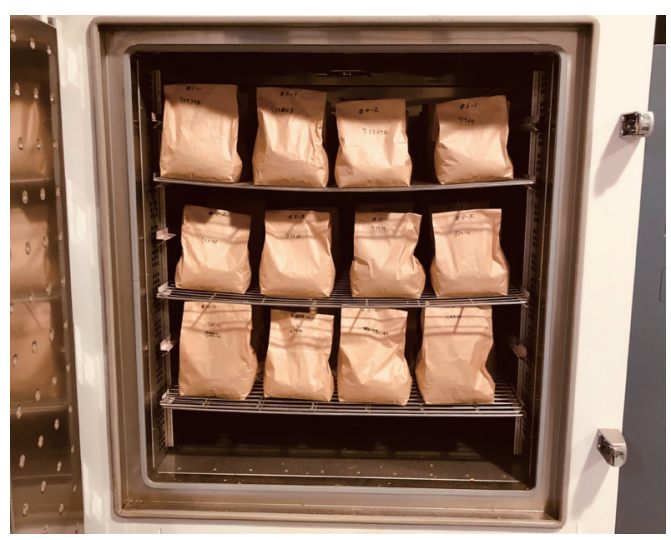

(b)

Fig. 3. (Color online) (a) Comminution of each forest residue pile and (b) oven drying of sample wood chip. 


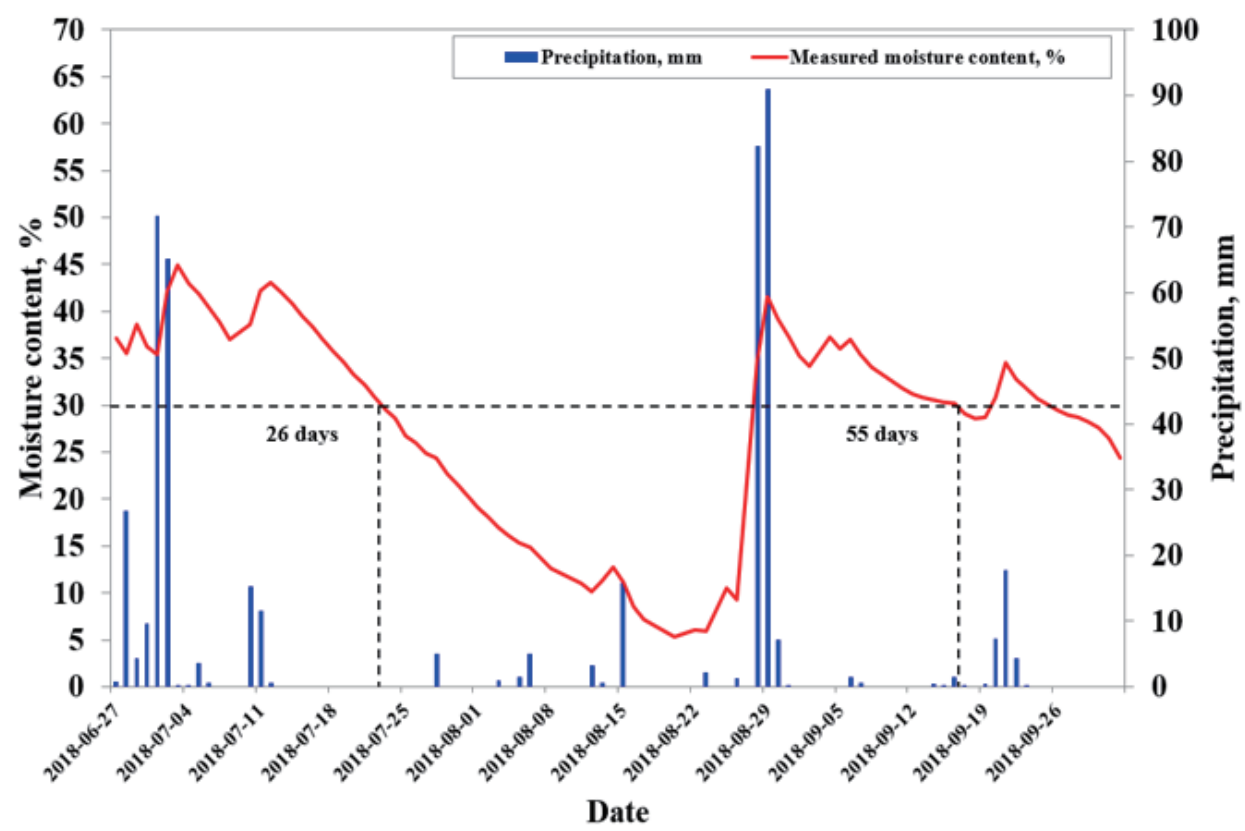

Fig. 4. (Color online) Measured moisture content of forest residue piles.

$30 \%$, as fuel materials with this moisture level are effective in producing heat at power plants. ${ }^{(19)}$ In the present study, the changes in moisture content had similar patterns to the changes in precipitation during the overall monitoring period (Fig. 4). In the summer, when the precipitation decreased, the moisture content of the material decreased, and when there was more precipitation, the material exhibited a higher moisture content. The minimum natural drying time to reach the target moisture content was approximately 26 days (Fig. 4). After first reaching the target moisture content, it increased again owing to the high precipitation during the rainy season. Approximately 55 days were required to reach the target moisture content. The total precipitation during the monitoring period was $548.43 \mathrm{~mm}$, and the mean temperature and relative humidity were $23{ }^{\circ} \mathrm{C}$ and $67 \%$, respectively. The moisture content of the measured pile irregularly increased from June 28 to July 12 and from August 23 to 30, 2018. This increase can be attributed to the high precipitation during the heavy rainy season in summer. However, a smooth decrease in the moisture content of the material was observed from July 12 to August 23 and from August 30 to September 27, with the former period showing a considerably greater decrease due to the higher temperature in summer. In August, the moisture content markedly increased by approximately $20 \%$ within a month (August 2018) after heavy rain. In a similar study, the moisture content of materials during natural drying was highly affected by the amount of precipitation and temperature in each season, and the moisture content increased with the higher precipitation and lower temperature in fall. ${ }^{(9,16)}$ Routa et al. ${ }^{(19)}$ also evaluated the changes in moisture content between uncovered fresh residues and those covered by paper materials for 8 months, and the lowest moisture content after natural drying was found in the fresh residues covered by paper materials. This result indicates that covering the materials can considerably affect the change in moisture content during natural drying. 


\subsection{Development and validation of prediction model for estimating moisture content of forest residues in natural drying}

A prediction model was developed to estimate moisture content based on meteorological factors. This allowed the investigation of the effects of meteorological factors on the natural drying of forest residues. In the development of the prediction model, a correlation analysis was first performed to investigate the multi-collinearity between meteorological variables. Correlation analysis revealed that the seven parameters (E-P, precipitation, evaporation, solar radiation quantity, cloud, wind speed, and effective humidity) were correlated with the daily moisture content (Table 1). Among them, E-P and evaporation were eliminated from the model owing to their high multi-collinearity with solar radiation quantity. Subsequently, the primary model was developed using the backward selection method, and cloud was eliminated from independent variables during modeling owing to its low $R^{2}$. Finally, the primary model was developed using five independent variables: daily moisture content change, daily precipitation, wind speed, effective humidity, and solar radiation quantity. The fitting rate of the developed prediction model was $85 \%$, which was statistically significant $(p<0.05$, Table 2$)$.

The initial prediction model was validated by comparing the measured and predicted moisture contents of the forest residue piles. The $t$-test results showed that there were no statistical differences between the measured and predicted moisture contents $(p>0.05$, Table 3$)$, and the relationship between the measured and predicted moisture contents for forest residues is shown in Fig. 5. The average absolute percentage difference between the measured and predicted moisture contents was only $14 \%$ and $R^{2}$ was 0.9019 . Therefore, it was concluded that the prediction model was valid and could be used to accurately predict the moisture content of forest

Table 1

Coefficient between $\mathrm{DMC}^{\mathrm{a}}$ and meteorological parameters.

\begin{tabular}{lc}
\hline Meteorological parameters & Pearson's $^{\mathrm{b}}$ \\
\hline${ }^{* *}$ Evaporation-Precipitation $(\mathrm{E}-\mathrm{P})$ & -0.755 \\
${ }^{* *}$ Precipitation & 0.731 \\
${ }^{* *}$ Evaporation & -0.617 \\
${ }^{* *}$ Solar radiation quantity & -0.606 \\
${ }^{* *}$ Cloud & 0.497 \\
${ }^{* *}$ Wind speed & -0.444 \\
${ }^{* *}$ Effective humidity & 0.422 \\
Atmospheric temperature & -0.188 \\
Ground-surface temperature & -0.163 \\
Spot atmospheric pressure & 0.075 \\
Humidity & -0.042 \\
\hline${ }^{a}$ DMC: daily moisture content, ${ }^{* *} p<0.01,{ }^{b}$ Pearson's correlation coefficient
\end{tabular}

Table 2

Primary multiple regression models for estimating daily moisture change from forest biomass.

\begin{tabular}{lccc}
\hline Multiple regression equations & $n$ & $R^{2}$ & $p$-value \\
\hline$M C_{i}=\left(M C_{i-1}\right)+0.129 \times P-0.318 \times W S-0.053 \times E H-0.095 \times S R+4.050$ & 65 & 0.854 & $<0.0001$ \\
\hline
\end{tabular}

$* M C$ : moisture content, $P$ : precipitation, $W S$ : wind speed, $E H$ : effective humidity, $S R$ : solar radiation quantity 
Table 3

Final multiple regression model for estimating daily moisture change from forest biomass.

\begin{tabular}{lccc}
\hline Multiple regression equation & $n$ & $R^{2}$ & $p$-value \\
\hline$M C_{i}=\left(M C_{i-1}\right)+0.089 \times P-0.775 \times W S-0.037 \times E H-0.098 \times S R+3.947$ & 91 & 0.786 & $<0.0001$ \\
\hline${ }^{*} M C$ : moisture content, $P$ : precipitation, $W S$ : wind speed, $E H$ : effective humidity, $S R$ : solar radiation quantity
\end{tabular}

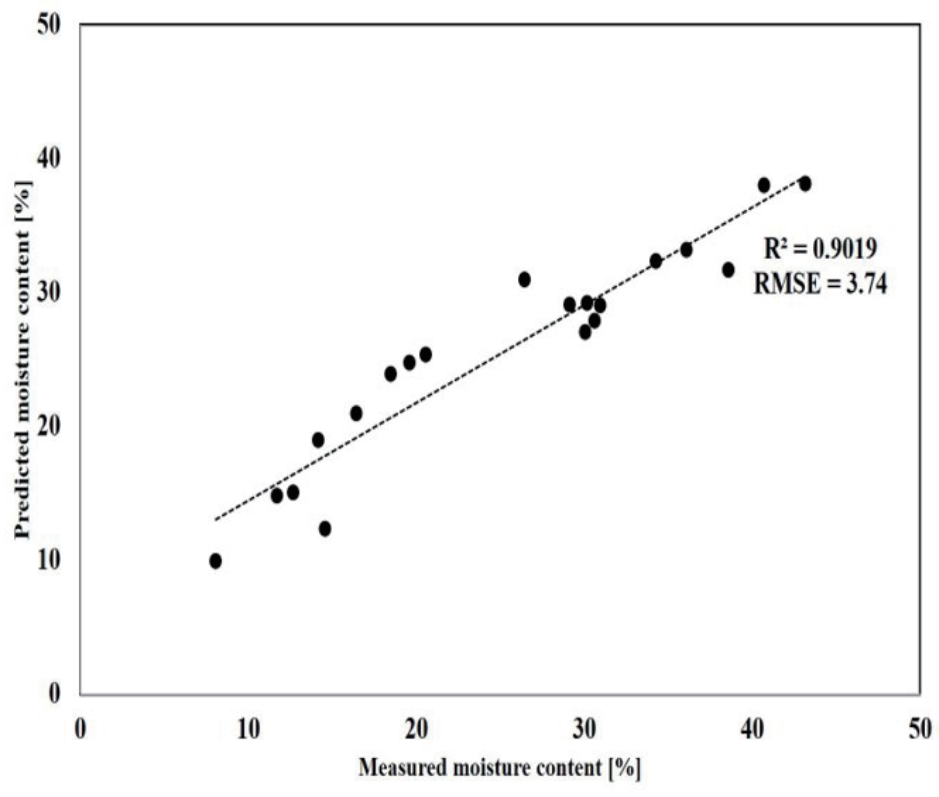

Fig. 5. Validation of initial prediction model.

residues using meteorological information for the natural drying period during open harvesting. Some differences observed in the initial model validation likely occurred because the dataset used contained data on weight losses, including both water and dry matter losses. In addition, the wide range of differences was likely caused by using the terrestrial meteorological data estimated by linear interpolation rather than the data obtained from the actual mountainous area. Therefore, directly installing the equipment for meteorological data collection in the natural drying area should be considered in future studies.

The final prediction model based on these results is presented in Table 3. The fitting rate of the final model was $79 \%$, which was statistically significant $(p<0.05)$. Among the independent variables of the model, the wind speed was found to have the most significant effect on the change in moisture content, followed by solar radiations quantity, precipitation, and effective humidity. Therefore, it was considered that the moisture content could be reduced more efficiently by stacking the piles of drying residues in places less closely surrounded by mountain slopes for better ventilation and solar radiation. To test the final model, it was adapted to the new dataset (45 forest residue piles) acquired from September 27, 2019 to April 16, 2020 (203 days) in the Pinus koraiensis forest (Fig. 6, Table 4). The initial moisture content of the forest residue piles was assumed to be $50 \% .{ }^{(4)}$ The average absolute difference between the measured and predicted moisture contents was $22.7 \%$, and the minimum and maximum differences were 1.8 


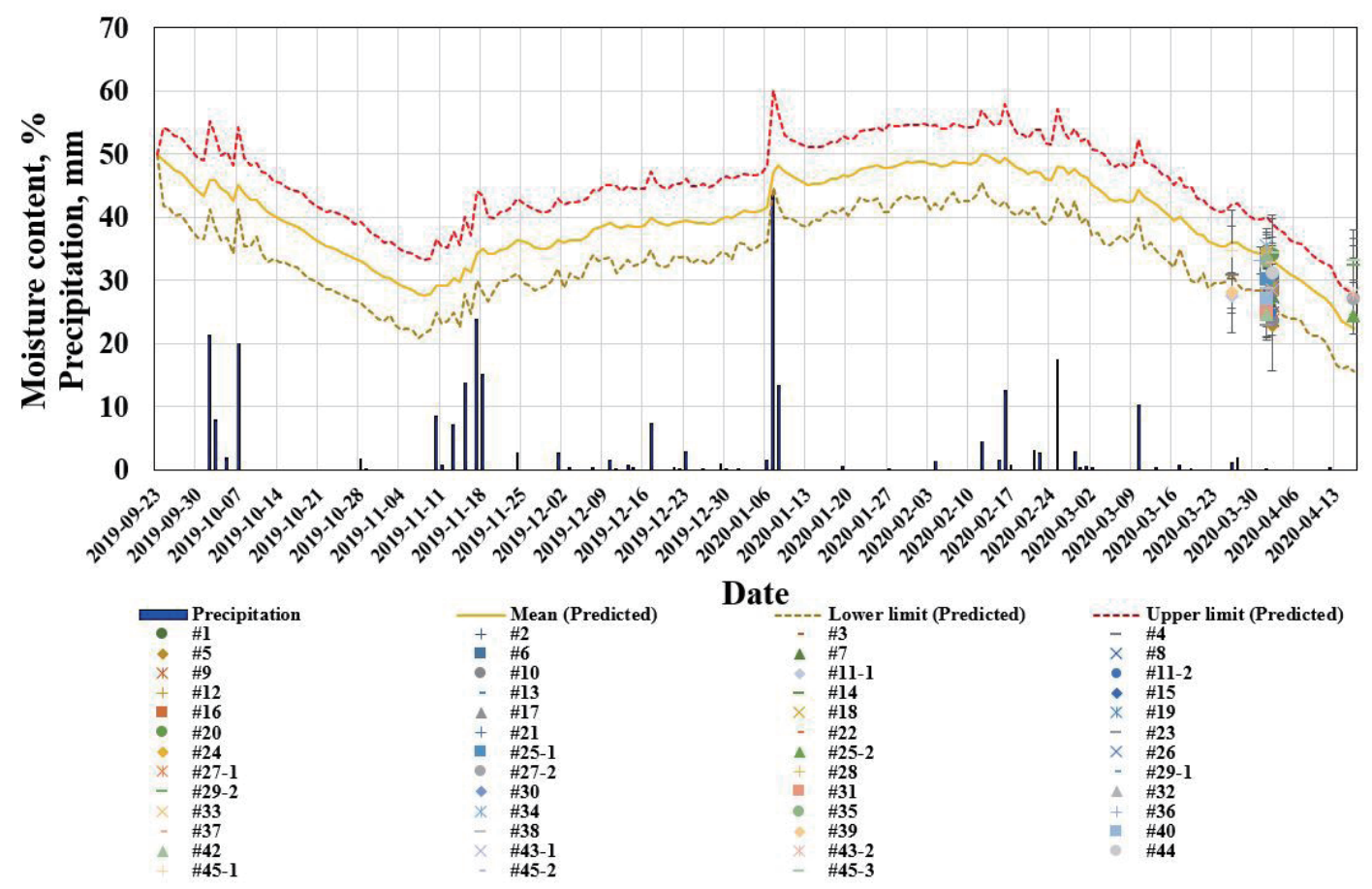

Fig. 6. (Color online) Measured and predicted moisture contents of forest residues.

Table 4

Difference between measured and predicted moisture contents for each forest residue pile.

\begin{tabular}{cccccc}
\hline \multirow{2}{*}{ Items } & \multirow{2}{*}{$n$} & \multicolumn{2}{c}{ Difference between measured and predicted moisture contents (\%) } & \multirow{2}{*}{ p-value } \\
\cline { 3 - 4 } & 45 & Average & Maximum & Minimum & \\
\hline
\end{tabular}

and $47.8 \%$, respectively (Table 4). Among the 45 forest residue piles, although every pile was dried under similar conditions, the range of differences among the piles was wide owing to the variations in their size, shape, and soil and irradiance conditionss. In addition, this prediction model is considered to have limited accuracy in estimating the moisture content change in different seasons because of the use of short-term monitoring data. Therefore, to enhance the accuracy of this prediction model in the future, a dataset containing at least one year of changes in monitored moisture content is required.

\section{Conclusions}

Owing to the increasing need for woody biomass fuel for energy use, its quality, particularly the moisture content, which directly affects the combustion effectiveness, has become important. Woody biomass produced from forest harvesting is dried to enhance its quality by lowering the moisture content. Normally, the natural drying of woody biomass in South Korea aims to achieve a moderate moisture content of $<30 \%$. However, it is difficult to determine the exact time required to dry the biomass and process it into fuels such as wood chips and pellets. 
Hence, to enable the estimation of the moisture content of woody biomass under certain meteorological conditions, we developed a moisture content prediction model using the monitored meteorological factors whose changes were consistent with weight changes of forest residue piles.

As expected, a strong correlation existed between the moisture change in biomass piles and the amount of precipitation. This is likely due to the fact that the monitored forest residue pile was not covered by any material and, therefore, the changes in moisture content reacted sensitively to precipitation. In addition, during the entire monitoring period, the time required to reach the target moisture content from a similar initial moisture content was approximately 9 days faster in summer than in fall owing to the higher temperature.

The moisture content prediction model was developed using meteorological factors such as daily moisture content change, daily precipitation, wind speed, effective humidity, and solar radiation quantity. Through the validation of this model using a total of 45 woody residue piles, we found that the average difference between the predicted and measured moisture contents was $22.7 \%$ and ranged from 1.8 to $47.8 \%$. However, a wide range of differences was observed (i.e., Table 4) owing to the differences in the size, shape, and soil, and irradiance conditions of the piles, as well as the use of short-term monitoring data (summer to fall). Therefore, future studies should be based on long-term monitoring involving various species of biomass and climates to enhance the applicability of prediction models for the natural drying of forest residues.

\section{Acknowledgments}

This research was funded by Korea Forest Service (National Institute of Forest Science) grant number FO0200-2018-01-2021.

\section{References}

1 K. T. Min and H. J. Ahn: Policy Tasks to Use Forest Biomass as a Local Energy Source (Korea Rural Economic Institute, Naju-si, 2021).

2 The Guidelines for Management and Operation of New and Renewable Energy Supply Mandatory System and Fuel Mixed Mandatory System (Ministry of Trade, Industry and Energy, Sejong, 2020) p. 10.

3 Development, Utilization and Supply of New and Renewable Energy Act (Ministry of Trade, Industry and Energy, Sejong, 2021) p. 17533.

4 J. H. Oh, J. W. Kim, and D. S. Cha: Forest Biomass Energy (National Institute of Forest Science, Seoul, 2011) p. 404.

5 T. L. Deboni, F. J. Simioni, M. A. Brand, and G. P. Lopes: Renew. Energy 135 (2019) 1291. https://doi. org/10.1016/j.renene.2018.09.039

6 D. Roser, M. Y. Blas, L. Sikanen, R. Prinz, D. Gritten, B. Emer, K. Vaatainen, and A. Erkkila: Biomass Bioenerg. 35 (2011) 4238. https://doi.org/10.1016/j.biombioe.2011.07.011

7 Specifications and Quality Standards of Wood Products (National Institute of Forest Science, Seoul, 2020) p. 3.

8 R. Jirjis: Biomass Bioenerg. 9 (1995) 181. https://doi.org/10.1016/0961-9534(95)00090-9

9 G. Erber, J. Routa, L. Wilhelmsson, J. Raitila, M. Toiviainen, J. Riekkinen, and L. Sikanen: Working Papers of the Finnish Forest Research Institute 297 (2014).

10 B. I. An and K. H. Ko: J. Korea Acad.-Ind. Coop. Soc. 22 (2021) 401. https://doi.org/10.5762/KAIS.2021.22.2.401

11 C. Brischke and A. O. Rapp: Wood Sci. Technol. 42 (2008) 663. https://doi.org/10.1007/s00226-008-0190-9

12 Y. S. Choi, J. S. Kim, and D. S. Cha: J. Korean For. Soc. 98 (2009) 426.

13 J. K. Gigler, W. K. P. van Loon, J. V. van den Berg, C. Sonneveld, and G. Meerdink: Biomass Bioenerg. 19 (2000) 153. 
14 M. Strandgard, M. Acuna, P. Turner, and L. Mirowski: Biomass Bioenerg. 147 (2021) 106000. https://doi. org/10.1016/j.biombioe.2021.106000

15 J. Y. Kim and B. R. Kim: The Wood Society of Korea Conf. Proc. (The Wood Society of Korea, 2019) p. 54.

16 D. W. Kim: Modeling Air-drying of Douglas-fir and Hybrid Poplar Biomass in Oregon (Oregon State University, 2012). https://ir.library.oregonstate.edu/concern/graduate thesis_or_dissertations/7p88ck794

17 A. Adebayo, J. Wang, B. Dawson-Andoh, J. F. McNeel, and J. P. Armstrong: Wood Fiber Sci. 41 (2009) 74.

18 A. R. Kizha and H. S. Han: Curr. For. Rep. 3 (2017) 202. https://doi.org/10.1007/s40725-017-0060-5

19 J. Routa, M. Kolstrom, J. Ruotsalainen, and L. Sikanen: Int. J. For. Eng. 26 (2015) 71. https://doi.org/10.1080/14 $\underline{942119.2015 .1012900}$ 